\title{
Experimental determination of thermal stability of metalorganic compounds in volcanic olivines
}

\author{
J.BRAU ${ }^{1 *}$, M.MATZKA $^{2}$, B.SCHEU ${ }^{1}$, N.HERTKORN ${ }^{2}$, \\ P.SCHMITT-KOPPLIN ${ }^{2,3}$, D.B.DINGWELL ${ }^{1}$ \\ ${ }^{1}$ LMU Munich, Department for Geo and Environmental \\ Sciences, 80333 Munich, Germany (*correspondance: \\ joanna.brau@min.uni-muenchen.de) \\ ${ }^{2}$ Helmholtz Center Munich, Research Unit Analytical \\ Biogeochemistry, 85764 Neuherberg, Germany \\ ${ }^{3}$ TUM, WZW, Institute of Analytical Food Chemistry, 85365 \\ Freising Freising/Weihenstephan, Germany
}

Organic compounds observed in silicate phases such as olivine may have been generated and selectively preserved from the earliest times of the solar system formation. We have investigated the thermal stability of such organic compounds under conditions which simulate those extant on the early Earth. This study focuses on natural volcanic olivines from the Kilauea eruptions of 1959 and 2018. Single mineral grains have been hand-picked for maximum absence of secondary phases such as melt. We used a high temperature gas-tight tube furnace under $\mathrm{CO}-\mathrm{CO}_{2}$ gas mixtures to simulate a defined reduced atmosphere with an oxygen fugacity of $10^{-12}$ bars. Temperatures are adjusted to be within the stability field of olivine at this oxygen fugacy and ranged from $950^{\circ} \mathrm{C}$ to $1350^{\circ} \mathrm{C}$. The samples were contained in Pt crucible tubes and held for dwell times of $1 \mathrm{~h}$ to $64 \mathrm{~h}$. The olivine grains were quenched by lifting the samples vertically out of the tube furnace, exposing them to ambient temperature. Using EPMA (electron microprobe analyzer), SEM (scanning electron microprobe) and RAMAN spectroscopy, we have mapped the state of the olivine samples. We observed that the composition of the individual mineral grains remained stable and homogeneous with thermal treatment. We also investigated the role of impurities and cracks in the natural olivine. The organic and metalorganic cargo (CHNOSMg compounds) of these olivines has been analyzed using FT-ICR-MS (Fourier transform ion cyclotron mass spectrometry) [1]. Preliminary results revealed systematic changes or organic molecular composition depending on duration and temperature of thermal treatment whose origins will be discussed.

[1] See abstract Matzka et al., Goldschmidt 2020 - Profiling of metalorganic compounds in volcanic olivines. 